\title{
As relações entre gestão, liderança e clima escolar: um estudo nas escolas municipais do Rio de Janeiro
}

Manuela Grill

Pontifícia Universidade do Rio de Janeiro (PUC-Rio), Rio de Janeiro/RJ - Brasil

OLIVEIRA, A.C.P. Gestão, liderança e clima escolar. Curitiba: Appris, 2018.

O livro Gestão, liderança e clima escolar, da autora Ana Cristina Prado de Oliveira, é fruto da sua tese de doutorado, defendida na Pontifícia Universidade Católica do Rio de Janeiro (PUC-Rio). A partir de uma abordagem quali-quanti, a autora busca compreender como a atuação do diretor pode influenciar a construção de um clima escolar, que favoreça o trabalho dos docentes e a proficiência dos alunos. Ao longo dos seis capítulos do livro, Ana Cristina Prado de Oliveira aborda em detalhes todo o processo de construção da sua pesquisa, realizada em 27 escolas do município do Rio de Janeiro, e apresenta os principais resultados de suas análises empíricas, que apontam interessantes conclusões acerca da relevância do trabalho do diretor para a construção de uma escola eficaz.

A importância dessa pesquisa se relaciona com os estudos sobre eficácia escolar que, desde a década de 1970, procuram compreender as características organizacionais e os processos escolares que estão relacionados a um melhor desempenho dos alunos. Situado no campo da sociologia da educação, esses estudos surgem como forma de contrapor as pesquisas realizadas nos anos 1960, que afirmavam que a escola não faz diferença, pois o que determinaria o futuro dos alunos seriam as suas características sociais. Além disso, as teorias da reprodução que enxergavam a escola como um espaço de reprodução e legitimação das diferenças sociais corroboraram o pessimismo pedagógico característico da época. Dessa forma, como abordado por Oliveira (2018), já na década de 1970, o campo da sociologia da educação começou a incorporar novos objetos e metodologias que auxiliavam nas investigações sobre os fatores intraescolares, que poderiam minimizar o efeito da origem social dos alunos e promover uma maior equidade e eficácia na oferta educacional, consolidando a tese de que a escola teria o poder, ainda que em menor escala, de influenciar o desempenho dos alunos. Nessa direção, a pesquisa da autora colabora com os 
estudos sobre eficácia escolar, ao passo que discute os aspectos da gestão e das condutas dos diretores, que podem resultar em melhorias no trabalho docente e na proficiência dos alunos.

Ao longo do primeiro capítulo, a autora apresenta os seus passos de revisão teórica e empírica acerca da gestão e do papel do diretor na formação do clima escolar. Através de um levantamento bibliográfico, realizado nos principais periódicos nacionais e internacionais, ela observou as pesquisas já elaboradas e que colaboraram para seu estudo, assim como as lacunas existentes na área e que poderiam ser preenchidas através de sua pesquisa. Além disso, discute as demandas e tarefas do diretor escolar, sendo elas administrativas, burocráticas, relacionais, entre outras. Trazendo tanto referências legais, em relação ao que a legislação prevê para o cargo de diretor, como definições conceituais dos principais autores que discutem sobre o tema, as demandas e atribuições dos gestores são apresentadas como forma de refletir sobre a complexidade de se gerir uma instituição escolar e de que forma o diretor pode administrar essas diferentes tarefas, a fim de priorizar o cumprimento da função educativa da sua escola, primordial entre as demais atribuições.

Em relação à metodologia da pesquisa, muitos pontos interessantes podem ser considerados. Em primeiro lugar, é preciso destacar o cuidado da pesquisadora ao detalhar todos os passos de elaboração do seu estudo empírico, deixando o leitor a par de todos os processos percorridos até chegar aos seus resultados, certificando alto grau de validade para sua pesquisa. Em segundo lugar, sem dúvida, a associação de métodos quantitativos e qualitativos aprofundou as suas análises, tornando o estudo mais completo e rico de contribuições para o campo da gestão escolar. Mesmo com todos os imprevistos relatados, comuns no cotidiano dos pesquisadores, a autora encontrou caminhos para responder a sua questão e obter os melhores resultados possíveis dentro da sua realidade e das limitações apresentadas. Ao longo do segundo e terceiro capítulos do livro, são apresentados os percursos traçados pela pesquisadora para chegar ao seu objetivo final, desde a definição do recorte de pesquisa, passando pela análise dos instrumentos disponíveis, até a construção de um novo questionário devido às limitações apresentadas nos instrumentos já existentes. 
Em relação à definição do campo de pesquisa, a autora descreve a rede de escolas municipais do Rio de Janeiro, através de dados quantitativos sobre o número de alunos matriculados, unidades existentes, professores atuantes e oferta do nível de ensino. É importante ressaltar que, de acordo com o Artigo 11 da Constituição Federal, como destacado por Oliveira (2018), os municípios possuem a responsabilidade de ofertar educação infantil (creches e pré-escolar) e ensino fundamental.

No Rio de Janeiro, a municipalização do ensino fundamental está em processo e já predomina na gestão desse segmento. Sendo assim, a escolha por essa rede se justifica, pela dimensão do seu atendimento e pela diversidade das suas configurações e arranjos destacados no decorrer do capítulo. Além disso, a autora decidiu focar sua pesquisa nas escolas que possuíam os dois segmentos do ensino fundamental, devido ao seu interesse em "analisar as estratégias de gestão adotadas pelos diretores de unidades que atendem a um público potencialmente maior, com uma diversidade no corpo discente (...) e no corpo docente (...)" (OLIVEIRA, 2018, p.60).

Para selecionar as escolas com essas características pré-estabelecidas, foi realizada uma análise dos dados da Prova Brasil e do Censo Escolar, identificando 163 escolas da rede municipal do Rio de Janeiro possíveis de serem estudadas. A partir dessa identificação, fez-se uma caracterização das escolas em relação ao nível socioeconômico dos alunos, o desempenho acadêmico nos testes de matemática da edição de 2013 da Prova Brasil, o perfil dos diretores e acesso ao cargo. Tendo em vista a impossibilidade de abranger as 163 escolas, a partir dos dados levantados, houve um processo de amostragem, em que foram selecionadas 42 escolas para serem pesquisadas, garantindo a representatividade da amostra.

Como já relatado, a autora optou por utilizar uma abordagem primeiramente quantitativa, para obter os dados à sua pesquisa e responder às questões formuladas. No entanto, a falta de informações disponíveis nas bases de dados já existentes, como a disponibilizada pelas edições da Prova Brasil, resultou na necessidade de formulação de um novo questionário que suprisse as demandas estabelecidas pela pesquisadora. A meu ver, essa limitação se transformou em uma das partes mais interessantes da pesquisa: a criação de um novo instrumento, que permitiu a compreensão das práticas dos diretores e 
da percepção dos professores sobre o clima escolar, de uma forma mais abrangente e cuidadosa. Sem dúvida, a elaboração desse instrumento contribuiu e continuará contribuindo fortemente para os estudos no campo da gestão escolar, que possui uma defasagem nas pesquisas quantitativas sobre 0 trabalho do diretor em relação ao trabalho docente e aos resultados dos alunos.

Em relação à construção de um novo survey, Oliveira (2018) dedicou o capítulo 3 do seu livro para detalhar o processo de sua formulação, assim como os referenciais teóricos que nortearam a produção do seu instrumento. Como destacado pela autora, a construção de um questionário passa pela identificação dos conceitos centrais, que serão posteriormente especificados em conceitos secundários, classificados quanto à sua operacionalização (latente ou observável) e, por fim, resultarão em itens para compor os questionários. Todo esse processo é sustentado pelas leituras relatadas no quadro teórico da pesquisa, que norteia a escolha dos conceitos. No caso dessa pesquisa, os conceitos centrais delimitados foram: gestão e liderança, clima escolar, contexto e caracterização sociodemográfica. A operacionalização dos itens em variáveis, ou seja, a forma como serão medidos (através de escalas, dimensões, reduções etc.) foi aprofundada pela autora no capítulo 4.

A validação do instrumento, aspecto importante dentro do processo de construção de um survey, é destacado pela autora como uma ação que "envolve estratégias para testar aplicabilidade, clareza e validade dos itens propostos para a construção dos dados que se pretende." (OLIVEIRA, 2018, p. 98). Nessa pesquisa, esse processo ocorreu em três momentos: um pré-teste assistido, validação dos pares dentro do grupo de pesquisa que a autora participa e, por fim, a validação de face (permite avaliar se os itens selecionados estão medindo o que realmente se deseja medir). A utilização dos três mecanismos como forma de ter clareza sobre a validade do instrumento construído demonstra, mais uma vez, a primazia da pesquisadora na busca de coletar os dados almejados. Além disso, no intuito de alcançar o maior número de respondentes, os questionários foram disponibilizados em duas versões: on-line e impressa.

Apesar de todo o cuidado relatado para que os atores escolares se sentissem confortáveis ao responder os questionários, o capítulo 4 apresenta alguns impasses vividos no momento da aplicação do Survey GESQ 2014, principalmente em relação a um retorno abaixo do esperado dos possíveis 
participantes. Nesse capítulo, Oliveira (2018) descreve todo o processo de contato com as escolas, o interesse ou não na participação da pesquisa, o baixo retorno de questionários respondidos e, por fim, a nova estratégia adotada de selecionar uma subamostra, de 27 instituições, para a elaboração do estudo. No entanto, ainda que a adesão tenha sido considerada baixa, um fator importante a ser considerado é que, na subamostra dessa pesquisa, havia uma média de 12 professores respondentes por escola. Tendo em vista que nos questionários da Prova Brasil essa média é de apenas seis respondentes nesse mesmo grupo de instituições, o Survey GESQ 2014 ainda possui um quadro representativo de docentes superior ao dessa avaliação externa.

O capítulo 4 ainda apresentou a construção e validação dos índices criados a partir dos questionários e que foram base do estudo estatístico exploratório na subamostra da pesquisa. Apesar de não ser possível fazer generalizações, devido à quantidade reduzida de escolas presentes no estudo, Oliveira (2018) conseguiu produzir resultados muito interessantes para compreender os aspectos do trabalho do diretor e do clima escolar que teriam influência na condição do trabalho do professor e na média de matemática dos alunos do $5^{\circ}$ ano na Prova Brasil. Utilizando o software SPSS para organização e análise dos dados coletados, Oliveira (2018, p.112) evidenciou “(...) quais são as variáveis (relacionadas ao trabalho do diretor e ao clima escolar) que apresentam uma relação significativa com a satisfação do professor no trabalho e com a aprendizagem dos alunos".

Os resultados apontados pela pesquisadora ao longo desse capítulo nos fazem compreender alguns aspectos das características da gestão que podem estar relacionados com a eficácia das escolas, o que demonstra, mais uma vez, a relevância desse estudo e como a participação de uma amostra mais representativa de instituições seria de enorme contribuição, não só para os estudos em gestão e eficácia escolar, mas para pensarmos em ações que pudessem ter reais efeitos para o ambiente escolar.

Sem dúvida, a leitura desses resultados pelos próprios gestores possibilitaria uma reflexão sobre as suas interversões pedagógicas, e, principalmente, sobre a importância das relações entre os atores escolares para a melhoria dos resultados dos alunos e para a satisfação dos docentes. 
A volta ao campo pela pesquisadora teve como principal objetivo validar e aprofundar as análises feitas a partir dos questionários, assim como tentar responder à novas questões que surgiram após os resultados do estudo quantitativo. Para selecionar as duas escolas que seriam analisadas foram considerados os resultados da Prova Brasil para o $5^{\circ}$ ano em matemática e desconsideradas as instituições que tiveram mudanças na equipe de direção a partir de 2015. Dessa forma, foram escolhidas duas escolas que possuíam nível socioeconômico similares (abaixo da média do grupo) e resultados na avaliação discrepantes $(233,09$ e 210,18). Além disso, foi levado em consideração o Índice de Reconhecimento do Trabalho da Direção e o Índice de Interação do Diretor analisado anteriormente através do estudo dos questionários. As escolas possuíam uma diferença considerável no Índice de Reconhecimento do Trabalho da Direção, e a volta ao campo, a partir da pesquisa qualitativa, ajudou a compreender que tipo de relações eram estabelecidas nesse espaço e a interferência desse índice nos resultados dos alunos. Outros índices também se mostraram discrepantes na comparação entre as duas escolas. Esse fato levou a pesquisadora a tentar compreender mais a fundo o porquê de duas escolas semelhantes em níveis socioeconômicos possuírem resultados educacionais tão discrepantes e em que medida essa realidade poderia estar relacionada com os resultados dos índices elaborados a partir do Survey GESQ 2014.

A pesquisa qualitativa que envolveu entrevistas e observações estilo "shadowing", também foi de extrema importância para aprimorar o Survey GESQ 2014, possibilitando a construção de novos itens para medir aspectos não incluídos anteriormente. Os resultados obtidos através das observações foram muito interessantes, ao passo que explicitaram a existência de dois estilos de lideranças bem distintos, que priorizavam diferentes aspectos na sua gestão, o que explica a diferença das respostas nos questionários aplicados. Além disso, os relatos e falas dos atores educacionais nos fazem refletir sobre o exercício desse cargo e as distintas tarefas que são cumpridas ao longo de um dia. A forma como a autora apresentou as diferentes tarefas exercidas pelo diretor em forma de tabela e explicitando o tempo destinado a cada uma delas foi muito interessante para compreender essa dimensão do trabalho da gestão. Ademais, conseguir relacionar as respostas dos questionários com o que estava sendo 
observado e analisado no próprio campo trouxe uma riqueza indiscutível para as análises e conclusões da autora.

A importância da leitura do livro Gestão, liderança e clima escolar de Ana Cristina Prado de Oliveira se justifica por diversos motivos. Não apenas pelo pioneirismo na construção de um novo questionário para diretores e professores que dimensiona questões não levantadas anteriormente, nem só pela escassez de pesquisas quantitativas que abordam as relações entre o trabalho do diretor e dos docentes com os resultados dos alunos, mas também pela integralidade do estudo desenvolvido, que, além de utilizar diferentes metodologias, ouviu diferentes atores educacionais, indicando a riqueza do seu trabalho.

Como aborda Ludke e André (1986), utilizar diferentes mecanismos para analisar o mesmo objeto possibilita que o pesquisador consiga enxergar o seu problema através de diferentes lentes e perspectivas. Ainda com todos os limites e desafios que ocorreram ao longo do caminho e que resultaram em novos recortes e delimitações, a autora conseguiu coletar dados que trouxeram importantes indicativos para o campo da gestão escolar. Para além da academia, essa leitura deve chegar ao "chão da escola", para que os gestores e professores se apropriem dos achados e reflitam sobre como o ambiente escolar, com todas as suas complexidades e nuances, pode ser um fator determinante para 0 resultado dos alunos.

Por fim, a leitura deste livro suscita algumas outras reflexões que abrangem não apenas os atores escolares, mas a sociedade como um todo. Compreender o papel da escola na aprendizagem dos alunos e o seu potencial em diminuir as desigualdades inicias dos estudantes é essencial em qualquer parte do mundo, no entanto, esse tema se torna ainda mais central quando falamos do Brasil. Em país tão desigual, em que as crianças vivem realidades tão distintas e têm experiências tão diferentes, como a escola pode ser um caminho para atenuar essas discrepâncias sociais? Compreender os fatores intraescolares que favorecem o aprendizado dos alunos e, consequentemente, fazem com que eles tenham trajetórias escolares mais longas, é primordial em um país onde a evasão é tão acentuada.

A conclusão das várias etapas da escolarização permite que os alunos tenham mais oportunidades dentro da sociedade e mais chances de mudar a sua realidade social. A pesquisa em eficácia escolar, abordada no início do livro 
e que permeia todo o estudo da autora, permite analisar os fatores que tornam as escolas mais eficazes em relação à aprendizagem dos alunos. Nesse sentido, se a gestão, a liderança e o clima escolar podem ser aspectos cruciais dentro desse processo de melhoria das instituições escolares e, consequentemente, dos resultados dos alunos, a questão central da pesquisa "Que relações podem ser estabelecidas entre o trabalho desempenhado pelo diretor, o trabalho desenvolvido pelos professores e o desempenho escolar dos alunos" (OLIVEIRA, 2018, p. 13) se torna ainda mais pertinente para a nossa realidade social.

\section{Referências bibliográficas}

LÜKDE, M.; ANDRÉ, M. Análise de dados e algumas questões relacionadas à objetividade nas abordagens qualitativas.

In:

Pesquisa

em educação: abordagens qualitativas. São Paulo: EPU, 1986. p.45-63 